\section{Newer Oral Antihyperglycemics: From Seinfeld to Breaking Bad}

In a previous Research Letter, ${ }^{1}$ we aired our grievances regarding dipeptidyl peptidase-4 (DPP-4) inhibitors by likening them to the popular television show Seinfeld. Similar to the trivial yet humorous experiences of Jerry and his friends, DPP-4 inhibitors basically do nothing with respect to clinically meaningful outcomes. Our metaanalysis of 3 large randomized controlled trials (RCTs) demonstrated that, compared with placebo, DPP-4 inhibitors have no effect on major adverse cardiovascular events (defined as cardiovascular death, nonfatal myocardial infarction, and nonfatal stroke with or without unstable angina), all-cause mortality, or hospital admission for heart failure in patients with type 2 diabetes mellitus who had or were at risk for cardiovascular disease. Since then, additional cardiovascular outcome trials involving DPP-4 inhibitors have been published.

Updating our previous search to January 2019, we identified 60 new articles, of which 2 RCTs met the same inclusion criteria as we used previously. ${ }^{1}$ One trial compared omarigliptin with placebo in 4202 patients (mean age 64 years, 70\% men) with type 2 diabetes and cardiovascular disease over a median of 1.8 years. ${ }^{2}$ The CARMELINA trial compared linagliptin with placebo in 6979 patients (mean age 66 years, 63\% men) with type 2 diabetes and cardiovascular disease over a median of 2.2 years. ${ }^{3}$ We updated our meta-analysis using a Mantel-Haenszel fixed-effect model when statistical heterogeneity was low (defined as $I^{2}<50 \%$ ) and a randomeffects model when statistical heterogeneity was high (defined as $I^{2} \geq 50 \%$ ) (Review Manager, version 5.3, Cochrane Collaboration).

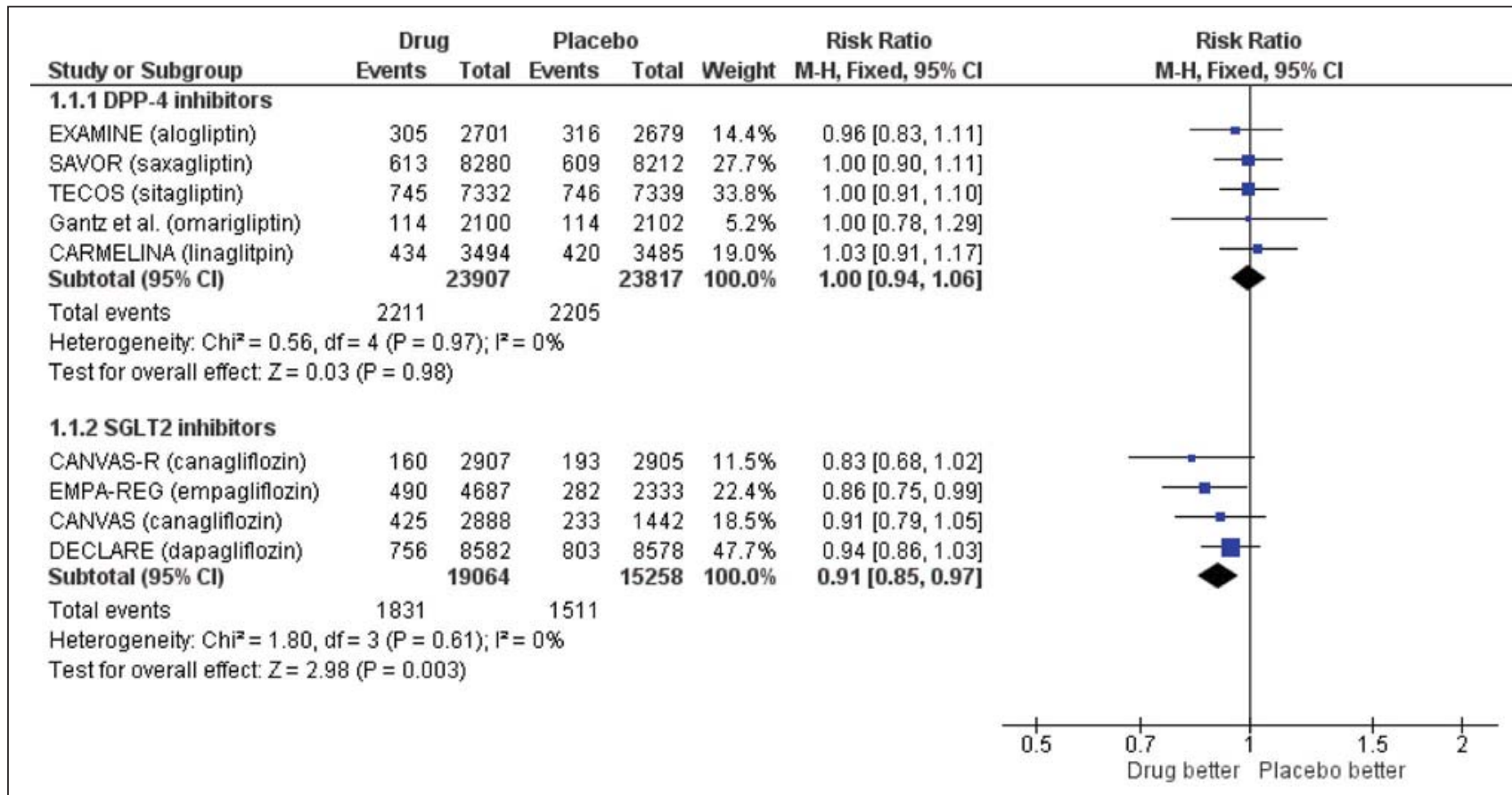

Figure 1. Forest plot for major adverse cardiovascular events (cardiovascular death, nonfatal myocardial infarction, nonfatal stroke, or unstable angina) in patients receiving dipeptidyl peptidase-4 (DPP-4) inhibitors and sodium glucose cotransporter-2 (SGLT2) inhibitors. EXAMINE trial for alogliptin = White and others, ${ }^{4}$ SAVOR trial for saxagliptin = Scirica and others, ${ }^{5}$ TECOS trial for sitagliptin = Green and others, ${ }^{6}$ trial for omarigliptin $=$ Gantz and others, ${ }^{2}$ CARMELINA trial for linagliptin = Rosenstock and others, ${ }^{3}$ CANVAS and CANVAS-R trials for canagliflozin $=$ Neal and others, ${ }^{8}$ EMPA-REG trial for empagliflozin $=$ Zinman and others, ${ }^{7}$, DECLARE trial for dapagliflozin $=$ Wiviott and others. ${ }^{9} \mathrm{Cl}=$ confidence interval, $\mathrm{df}=$ degrees of freedom, $\mathrm{M}-\mathrm{H}=\mathrm{Mantel}-\mathrm{Haenszel}$. 


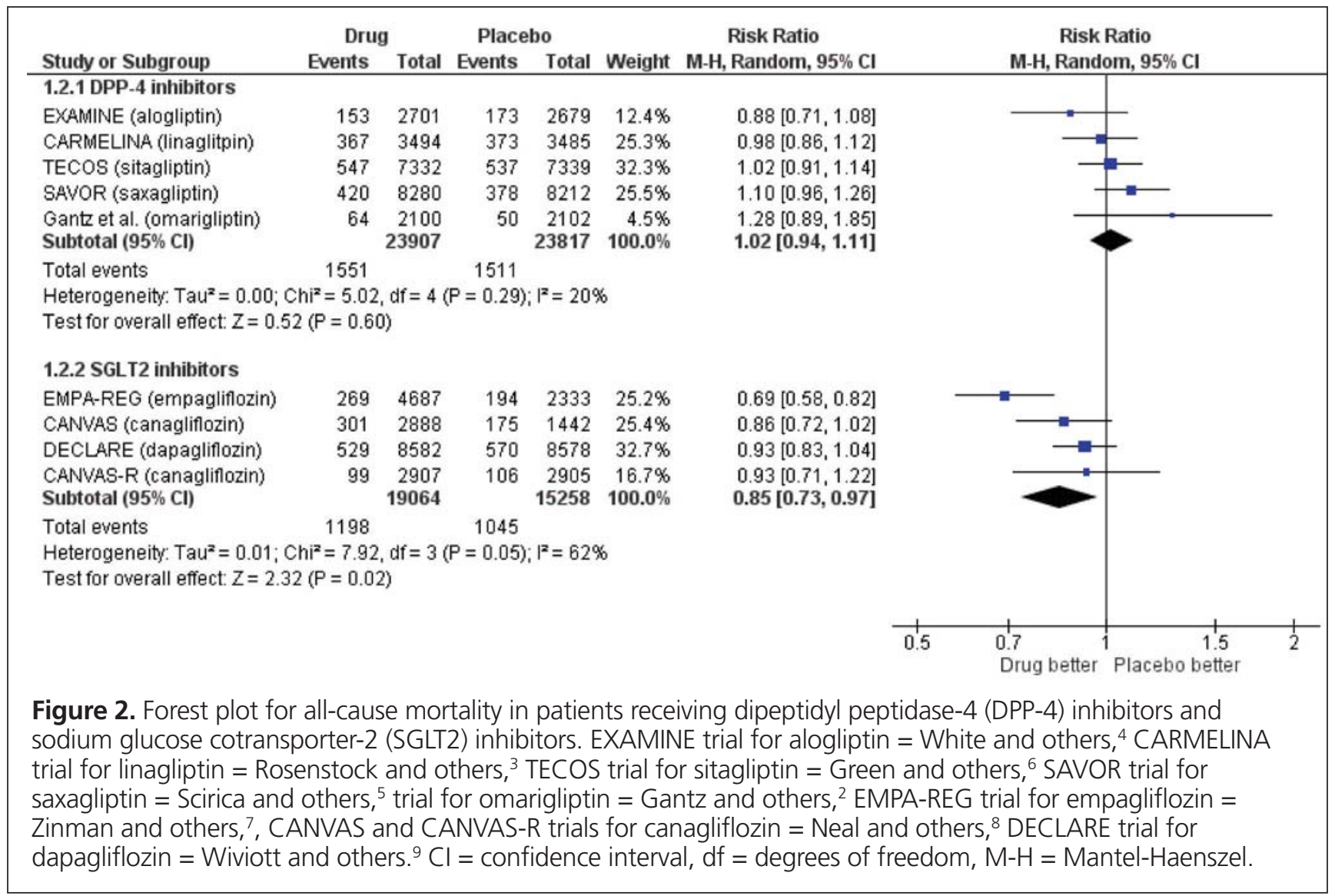

The overall results from the fixed-effect and random-effects models were similar. As with our previous analysis, there was no significant difference in major adverse cardiovascular events (risk ratio [RR] 1.00, 95\% confidence interval [CI] 0.94-1.06; Figure 1), all-cause mortality (RR 1.02, 95\% CI 0.94-1.11; Figure 2), or hospital admission for heart failure (RR 1.04, 95\% CI 0.95-1.15). These data corroborate our previous conclusion that DPP-4 inhibitors represent the Seinfeld of oral antihyperglycemics.

Another class of oral antidiabetic drugs - the sodium glucose cotransporter-2 (SGLT2) inhibitors- has now emerged, with more promising evidence. We searched PubMed using the terms "sodium glucose cotransporter-2 inhibitors" and "cardiovascular disease" for the period December 2008 to January 2019 using the same inclusion criteria. ${ }^{1}$ Of the 54 articles identified, 3 RCTs were included, all of which had enrolled patients with type 2 diabetes who had or were at risk for cardiovascular disease. ${ }^{7-9}$ The EMPA-REG OUTCOME trial compared empagliflozin with placebo in 7020 patients (mean age 63 years, $71 \%$ men). ${ }^{7}$ The CANVAS/CANVAS-R trials compared canagliflozin with placebo in 10142 patients (mean age 63 years, $64 \%$ men). ${ }^{8}$ The DECLARE-TIMI 58 trial compared dapagliflozin with placebo in 17160 patients (mean age 64 years, 63\% men). ${ }^{9}$ Median follow-up was 3.1 to 4.2 years. We performed a meta-analysis with these trials $(n=34322)$, which showed that SGLT2 inhibitors significantly reduced major adverse cardiovascular events (RR 0.91,
95\% CI 0.85-0.97; Figure 1) and hospital admission for heart failure (RR 0.71, 95\% CI 0.62-0.80). These appear to be class effects. All-cause mortality was significantly lower with the SGLT2 inhibitors (RR 0.85, 95\% CI 0.73-0.97; Figure 2), but the substantial heterogeneity $\left(I^{2}=62 \%\right)$ and more pronounced effect with empagliflozin suggest that this effect may be unique to that agent. These results are consistent with another recent meta-analysis. ${ }^{10}$

However, despite these encouraging results, SGLT2 inhibitors may be "breaking bad". We are not referring here to criminality, as with Walter White on the hit television drama of the same name, but rather to the inconsistent efficacy and unexpected adverse events associated with these agents. Much like a pizza on a roof, we believe these concerns cannot be ignored. Although they have not been encountering Breaking Bad-style violence, patients taking SGLT2 inhibitors are unexpectedly experiencing fractures and undergoing amputations. A recent meta-analysis of the aforementioned trials showed an increased risk of amputations with SGLT2 inhibitors (hazard ratio [HR] 1.26, 95\% CI 1.06-1.51), although these results had substantial heterogeneity $\left(I^{2}=79 \%\right)$ and were primarily driven by canagliflozin. ${ }^{10}$ Fractures were numerically higher with SGLT2 inhibitors (HR 1.08, 95\% CI 0.98-1.20), with moderate heterogeneity $\left(I^{2}=42 \%\right)$, and this result was again primarily driven by canagliflozin. In addition, diabetic ketoacidosis was significantly higher with SGLT2 inhibitors (HR 2.20, 95\% CI 1.25-3.87). 
On the basis of these analyses, we emphatically recommend SGLT2 inhibitors over DPP-4 inhibitors in the management of type 2 diabetes. The cardiovascular efficacy data must be respected. However, as with any new class of medications, SGLT2 inhibitors have the potential to "break bad". With inspiration from Walter White, if that's true, and if we don't know whether any of these agents are more harmful than the others, then maybe our best course would be to tread lightly. Even though future studies are needed to refine their net clinical effect, using SGLT2 inhibitors remains far removed from wearing a black porkpie hat and adopting the pseudonym "Heisenberg". Despite possibly "breaking bad" for some noncardiovascular outcomes, at least the SGLT2 inhibitors have some measurable clinical benefit, which is more than can be said for the DPP-4 inhibitors.

\section{References}

1. Barry AR, Turgeon RD. DPP-4 inhibitors: the Seinfeld of oral antihyperglycemics. Can J Hosp Pharm. 2016;69(3):253-4.

2. Gantz I, Chen M, Suryawanshi S, Ntabadde C, Shah S, O'Neill EA, et al. A randomized, placebo-controlled study of the cardiovascular safety of the once-weekly DPP-4 inhibitor omarigliptin in patients with type 2 diabetes mellitus. Cardiovasc Diabetol. 2017;16:Article 112.

3. Rosenstock J, Perkovic V, Johansen OE, Cooper ME, Kahn SE, Marx N, et al.; CARMELINA Investigators. Effect of linagliptin vs placebo on major cardiovascular events in adults with type 2 diabetes and high cardiovascular and renal risk: the CARMELINA randomized clinical trial. JAMA. 2019;321(1):69-79.

4. White WB, Cannon CP, Heller SR, Nissen SE, Bergenstal RM, Bakris GL, et al.; EXAMINE Investigators. Alogliptin after acute coronary syndrome in patients with type 2 diabetes. $N$ Engl J Med. 2013; 369(14):1327-35.

5. Scirica BM, Bhatt DL, Braunwald E, Steg PG, Davidson J, Hirshberg B, et al.; SAVOR-TIMI 53 Steering Committee and Investigators. Saxagliptin and cardiovascular outcomes in patients with type 2 diabetes mellitus. N Engl J Med. 2013;369(14):1317-26.
6. Green JB, Bethel MA, Armstrong PW, Buse JB, Engel SS, Garg J, et al.; TECOS Study Group. Effect of sitagliptin on cardiovascular outcomes in type 2 diabetes. N Engl J Med. 2015;373(3):232-42.

7. Zinman B, Wanner C, Lachin JM, Fitchett D, Bluhmki E, Hantel S, et al.; EMPA-REG OUTCOME Investigators. Empagliflozin, cardiovascular outcomes, and mortality in type 2 diabetes. $N$ Engl J Med. 2015; 373(22):2117-28

8. Neal B, Perkovic V, Mahaffey KW, de Zeeuw D, Fulcher G, Erondu N, et al.; CANVAS Program Collaborative Group. Canagliflozin and cardiovascular and renal events in type 2 diabetes. N Engl J Med. 2017; 377(7):644-57.

9. Wiviott SD, Raz I, Bonaca MP, Mosenzon O, Kato ET, Cahn A, et al.; DECLARE-TIMI 58 Investigators. Dapagliflozin and cardiovascular outcomes in type 2 diabetes. $N$ Engl J Med. 2019;380(4):347-57.

10. Zelniker TA, Wiviott SD, Raz I, Im K, Goodrich EL, Bonaca MP, et al. SGLT2 inhibitors for primary and secondary prevention of cardiovascular and renal outcomes in type 2 diabetes: a systematic review and metaanalysis of cardiovascular outcome trials. Lancet 2019;393(10166):31-9.

Arden R Barry, BSc, BSc(Pharm), PharmD, ACPR

Chilliwack General Hospital, Lower Mainland Pharmacy Services Chilliwack, British Columbia

Faculty of Pharmaceutical Sciences, The University of British Columbia Vancouver, British Columbia

Ricky D Turgeon, BSc(Pharm), PharmD, ACPR

Vancouver General Hospital, Lower Mainland Pharmacy Services Vancouver, British Columbia

Competing interests: None declared.

Funding: None received.

CJHP Subscription Rates 2020 /

Prix d'abonnements au JCPH 2020

The Canadian Journal of Hospital Pharmacy (CJHP) is included as a benefit of CSHP membership. All prices are in Canadian funds.

L'abonnement à le Journal canadien de la pharmacie hospitalière (JCPH) est inclus dans les droits d'adhésion à la SCPH. Tous les prix sont en dollars canadiens.

\begin{tabular}{|lll|}
\hline $\begin{array}{l}\text { Subscriber group / } \\
\text { Groupe d'abonnés }\end{array}$ & $\begin{array}{l}\text { Individual Subscription / } \\
\text { Abonnement individuel }\end{array}$ & $\begin{array}{l}\text { Institutional Subscriptions / } \\
\text { Abonnement institutionnel }\end{array}$ \\
$\begin{array}{lll}\text { Nonmembers / } \\
\text { Non-membres }\end{array}$ & $\begin{array}{l}\$ 160.00 \text { per year, plus GST or HST } \\
160,00 \$ \text { par an, plus TPS ou TVH }\end{array}$ & $\begin{array}{l}\text { Tiered pricing is available } \\
\text { Des prix différenciés sont disponibles }\end{array}$ \\
\hline
\end{tabular}

If you would like to purchase a subscription, please fill-out our Subscription Form, which can be found on the CJHP website: www.cjhp-online.ca, under "Subscriptions". Please direct any comments or questions to publications@cshp.pharmacy.

Si vous désirez vous abonner, veuillez remplir le formulaire d'abonnement du JCPH. Vous pouvez l'obtenir en visitant le site Web du JCPH : www.cjhp-online.ca. Pour tout commentaire ou toute question, veuillez vous adresser à publications@cshp.pharmacy. 